\title{
Zitosoleko lipido-tanten sorrera eta erabilera
}

\section{(Formation and utilization of cytosolic lipid droplets)}

\author{
Hiart Navarro-Imaz ${ }^{1}$, Lino Arisqueta ${ }^{2}$, Yuri Rueda ${ }^{1}$, Olatz Fresnedo ${ }^{1 *}$ \\ ${ }^{1}$ Fisiologia Saila, \\ Euskal Herriko Unibertsitatea UPV/EHU \\ ${ }^{2}$ Escuela de Medicina, \\ Universidad Internacional del Ecuador (UIDE) \\ *olatz.fresnedo@ehu.eus
}

DOI: 10.1387/ekaia.16388

Laburpena: Lipido-tantak klasikoki lipido-biltegi inertetzat hartu badira ere, gaur egun benetako organulutzat hartzen dira, beren konplexutasunagatik eta metabolismoan eta zelulen beste fenomenoetan dituzten zereginengatik. Erretikulu endoplasmatikoan sortu eta bertatik askatu ondoren, beren bizitzan zehar hazi egiten dira, lipidoen eta proteinen transferentzia egiten dute, fusio prozesuetan hartzen dute parte eta elkarrekintza espezifikoak izaten dituzte beste organuluekin. Gordetzen dituzten lipidoak erregai zein beste molekula batzuen aitzindari gisa erabiltzen dira, eta horretarako lipolisi eta lipofagia prozesuen bidez askatzen dituzte modu erregulatuan. Lan honetan laburki aztertzen dira prozesu horiek eta lipido-tantek betetzen dituzten funtzio ezkanonikoak.

Hitz gakoak: lipido-tantak, lipidoen metaketa, funtzio ezkanonikoak.

Abstract: Although lipid droplets (LD) have traditionally been considered inert lipid deposits nowadays they are considered true organelles given their complexity and involvement in metabolism and other cellular processes. LDs originate in endoplasmic reticulum and after release they show growth, transference of lipids and proteins, fusion or specific interactions with other organelles. Lipids stored in LDs can be used as fuel or metabolic precursors, and for such purposes they are released in tightly controlled lipolysis or lipophagy processes. This work summarises all these aspects as well as other non-canonical LD functions.

Keywords: lipid droplets, lipid storage, non-canonical functions. 


\section{SARRERA}

Zitosoleko lipido-tantak (LT), lipido-gorputz edo adiposoma ere deituak, nukleodun zelula gehienetan agertzen diren arren, bereziki nabarmenak dira ehun batzuetan (lipidoen metabolismoarekin zerikusia dutenetan) eta egoera batzuetan. LTen egituran bi eremu bereiz daitezke: gune anhidroa eta gainazal anfipatikoa (1 Irudia). Gunean triazilglizerolak (TG) eta kolesteril esterrak bezalako lipido neutroak dira nagusi. Azala mintzetako lipidozko geruza bakun batez eta horri loturiko proteinaz osatuta dago. Proteina horien kopurua eta konposaketa oso aldakorrak dira ehun mota eta egoera fisiologikoaren arabera. Organulu horren azterketa klasikoak lipidoen metaketan espezializatutako ehunetan egin izan dira, adibidez ehun adiposoan. Horregatik lipidoen metaketarako eta mobilizaziorako zelulabarrunbetzat hartu dira betidanik. Erregaien hornikuntzaz eta haien erabilpenaren erregulazioaz gain, LTek beste funtzio asko betetzen dituzte.

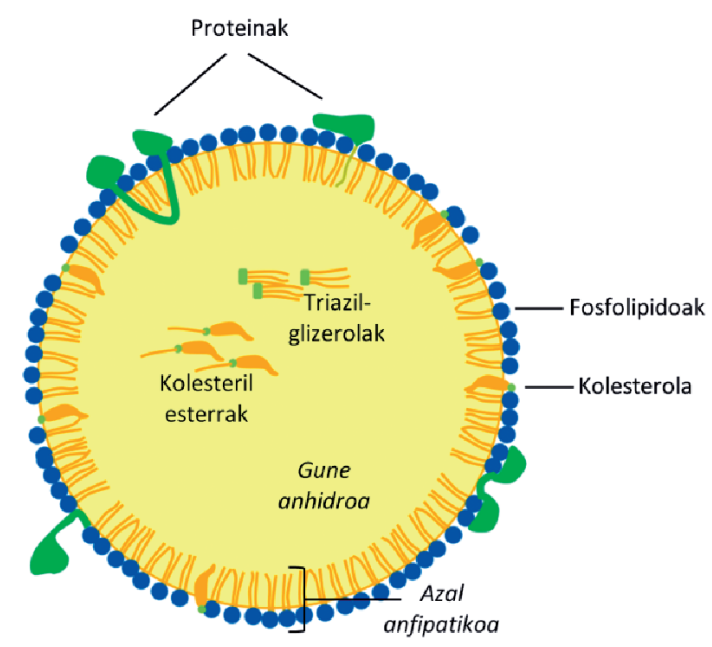

1. irudia. Zitosoleko lipido-tanten egitura. Gune anhidroak lipido neutro hidrofobikoak dauzka. Azaleko geruza erdi-mintz bat da, izaera anfipatikoa duten lipidoz osatua. Bertan zenbait proteina daude ainguratuta edo itsatsita.

\section{BIOGENESIA ETA HAZKUNTZA}

LTak erretikulu endoplasmatikoan (EE) sortzen dira. Bertan daude, mintzari lotuta, TGen eta kolesteril esterren (orokorrean, esteril esterren) sintesi bideetako azken urratsak katalizatzen dituzten entzimak: diazilglizerido aziltransferasa (DGAT) eta azil-A koentzima:kolesterol aziltransferasa (acyl-coenzyme A:cholesterol acyltransferase edo ACAT). Sortutako pro- 
duktuak bigeruzaren erdialdean metatuz doazen neurrian, mintzean konkor bat sortzen doa; konkor hori tanta txiki bezala aska daiteke. EEko mintzaren zitosol aldeko geruzak tantaren azal anfipatikoa osatzen du (2A Irudia).

Prozesu hori espontaneoki gerta daitekeela frogatu bada ere [1], segur aski tanten sorreran proteina espezifikoek hartzen dute parte. LTak EEaren mintzetik kimatu daitezen, EEaren mintzaren zitosol aldeko geruza era egokian okertu behar da; okerdura mintzaren lipido konposizioaren araberakoa da. Esaterako, diazilglizerolek (DG) konbexutasuna eragiten dute eta horrela LTen sorrera bultzatzen dute [2]. Gainera, konbexutasuna eragin edota egonkortu dezaketen proteina espezifikoak erakartzen dituzte bertara (2A irudia), ondorioz LTa zitosolerantz askatuko da eta ez lumenerantz. Horrelako funtzioetan dihardute perilipina (PLIN) batzuek. PLIN proteinek LTekin elkartzen diren 5 kideko proteina familia osatzen dute. PLIN1 eta PLIN2 konstitutiboak dira eta beti LTei lotuta agertzen dira. PLIN3, 4 eta 5 aldiz fakultatiboak dira: zitosolaren eta LTen artean lekualdatzen dira zelularen beharrizanen edo egoera metabolikoaren arabera.

Oraindik ez da zehaztu LTak EEaren leku jakin batzuetan edo mintz osoan zehar zoriz sortzen ote diren, baina TGen sorrera estimulatzen denean, EEren mintzeko leku jakin batzuetan proteina espezifikoak biltzen dira modu koordinatuan eta sekuentzialean [3]. Lehen elkartzen direnen artean kate luzeko azil-A koentzima sintetasa 3 (acyl-coenzyme A synthetase, long chain, 3 edo ACSL3) dugu; ACSL3 inhibitzean gantz-azidoek eragindako LT-sorrera ekiditen da. PLIN2 eta 3 ere LTen sorkuntza-leku horietan elkartzen dira, DGetan aberatsak diren mintz-eremuetan. Bertan, DG erabiliz DGATk sortutako TGak metatu egingo dira.

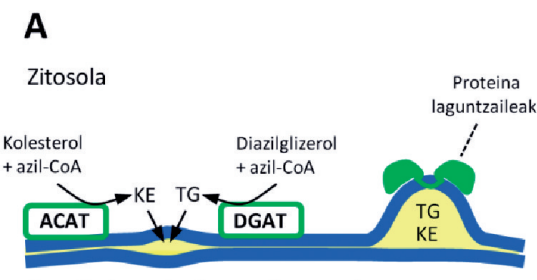

Erretikulu endoplasmatikoaren lumena

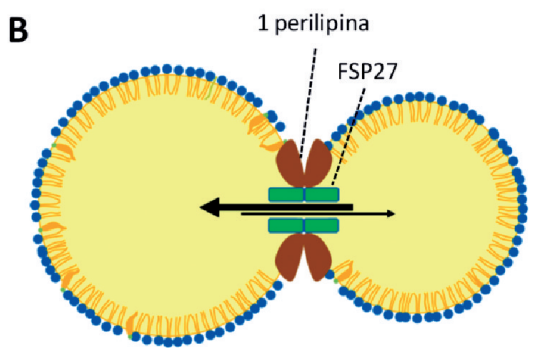

2. irudia. Lipido-tanten biogenesia eta hazkuntza. A: Azil-A koentzima:kolesterol aziltransferasak (acyl-coenzyme A:cholesterol acyltransferase edo ACAT) eta diazilglizerol aziltranferasak (DGAT) sortutako lipido esterifikatuak (kolesteril esterrak (KE) eta triazilglizerolak (TG)) erretikulu endoplasmatikoko mintzaren bi geruzen artean metatzen dira. Sortutako lodiunea zitosol aldeko konkor modura hazten da geruza anfipatikoaren konposizioari eta proteina espezifikoen laguntzari esker. B: Lipido-tanten hazkuntza mekanismoetako bat FSP27 proteinak bideratutako lipidoen transferentzia da. 
Behin EEko mintzetatik askatuta, LTak zenbait mekanismoren bitartez hazten dira: LTen arteko lipido hidrofobikoen transferentziaren eta lipidoen in situ sintesiaren bidez. Transferentzia prozesuan FSP27 (fat specific protein of $27 \mathrm{kDa} ; 27 \mathrm{kDa}$-eko gantzaren proteina espezifikoa) proteinak hartzen du parte [4], PLIN1 eta RAB8 (Ras-related protein 8; Ras-ekin erlazionatutako proteina 8) proteinen laguntzarekin [5, 6]. FSP27 LTen arteko kontaktu guneetan biltzen da; zubi funtzioa betetzen duen egitura bat eratu eta lipidoak LT txikienaren gunetik handienarenera lekualdatzen dira (2B irudia). Horrelako mekanismoen bidez sortzen dira adipozitoetako LT unilokilarrak (zelularen zitoplasma osoa betetzen duten LT erraldoiak). Bigarren mekanismoan LTak beste tantekin elkartu gabe handitzen dira, sortu berriak diren lipidoak gehituz. Lipidoen ekoizpenerako prozesuak LTetan bertan edo beste organuluetan (batik bat EEan) kokatutako aziltransferasek gauzatu ditzakete. Adibidez, deskribatu da ugaztunen zeluletan DGAT2, DGAT entzimaren isoentzimatako bat, LTetan egon daitekeela [7].

Lipidoen gehikuntzak eragindako hazkuntzaz gain, LTak proteinatan aberasten dira heltze prozesuan. LTetarako eta LTetatiko proteinen trafikoari buruzko ikerkuntza asko egin diren arren, prozesu horien ezagumenduak hutsune asko dauzka. Proteinak LTetara biderarazten dituen zenbait aminoazido-sekuentzia labur identifikatu da [8,9]. Sekuentzia horiek urkila hidrofobiko bat edukitzen dute helize kationiko edo anfipatiko baten alboan. Oso aztertua izan da glizerolipidoen biosintesi bideko GPAT4 ( $g l y$ cerophosphate acyltransferase 4; glizerofosfato aziltransferasa 4) entzimaren sekuentzia espezifikoa [10]. Kasu horretan translokazio-sekuentziak entzimaren EEaren eta LTen arteko lekualdaketa erregulatzen du. LTetara doazen beste proteina batzuen jatorria izan daitezke zitosola (adibidez zenbait PLINena) edo nukleoa (esaterako fosfatidilkolinaren biosintesi bideko CTP:fosfokolina zitidiltransferasarena) $[11,12]$. EEtik ez datozen proteinen garraioan badirudi garrantzitsuak direla proteina horien eta LTetako osagaien arteko afinitateak.

Proteinak LTetara garraiatzeko beste mekanismo konplexuagoak ere badaude. Adibidez deskribatu da COPI (coat complex protein I; estaltzekonplexuko proteina I) izeneko proteinak, EEaren eta Golgi aparatuaren arteko garraio-besikuletan diharduenak, ATGL (adipozitoetako triazilglizerol lipasa) entzimaren LTetarako garraioan parte hartzen duela [13].

\section{SUNTSITZEA}

LTen suntsitze prozesua oinarrizkoa da lipidoen metabolismoan. Gaur egun ezaguna da zelula eukariotikoek bi prozesu kataboliko nagusi erabiltzen dituztela LTen edukia mobilizatzeko: lipolisia eta lipofagia. LTen katabolismorako mekanismoa zelula motaren eta egoera fisiologikoaren 
araberakoa da. Morfologiaren eta mekanismoaren aldetik ezberdinak izan arren, LTen lipolisiak eta lipofagiak modu kooperatiboan jardun lezaketela proposatu da [14].

Lipolisiaren inguruan dakigun gehiena adipozitoetan egindako ikerketetan aurkitu da. Ehun adiposoko TGen hidrolisian eta bere erregulazioan hormonekiko sentikorra den lipasa (HSL) klasikoak eta PLINek hartzen dute parte, baina horietaz gain azken urteotan lipasa berriak identifikatu eta karakterizatu dira, besteak beste ATGL. Adipozitoetako LTetan TGen hidrolisia hiru lipasaren ekintzari esker gertatzen da (3A Irudia). Lehenengo ATGLk, jarraian HSLk eta azkenik monoazilglizerol (MG) lipasak jokatzen dute, hurrenez hurren TGak, DGak eta MGak hidrolizatuz, gantz-azidoak eta glizerola emateko. Adipozitoen lipolisia oso estuki erregulatutako prozesua da. Aktibatzaile garrantzitsuenak katekolaminak dira, HSLren aktibazioa bultzatzen dutenak. Estimulatu gabeko egoeran PLIN1 proteinak CGI-58 (comparative gene identification 58; gene-identifikazio konparatiboa 58) eta ATGL bahituta mantentzen ditu eta ondorioz, lipolisia inhibitzen du. Estimuluaren eraginez, aldiz, HSL eta PLIN1 aktibatu egiten dira eta CGI-58 askatu egiten da, eta ondorioz LTen guneko TGak ATGLrentzat eskuragarri bilakatzen dira [1].

Adipozitoetan ez bezala, oso urria da gainerako ehunetako TGen mobilizazioaren inguruan dagoen informazioa, baina ATGLren homologoen identifikazioak iradokitzen du beste lipasek funtzio lipolitiko garrantzitsua izan dezaketela bestelako ehunetan [1].

Azken urteotan, autofagia identifikatu da LTak berritzeko mekanismo gisa. Suntsipen prozesu konplexu horretan lisosomek hartzen dute parte 32 gene baino gehiagoren sare batek koordinatuta [15]. LTen autofagia lipofagia bezala ezagutzen da, eta 3 mota bereiz daitezke: makroautofagia, mikroautofagia eta fase geldikorreko autofagia. Azken biak legamietan deskribatu dira nagusiki [16].

Ondo definituriko lehendabiziko lipofagia prozesua hepatozitoetan deskribatu zen eta makroautofagia motakoa da (3B Irudia). Makroautofagian mintz bikoitz batek LTa inguratzen du eta autofagosoma bat eratzen da; hori jarraian lisosomekin fusionatzen da bere edukiaren degradaziorako [17]. Proposatu da hainbat proteinak har lezaketela parte lisia jasango duten zitosoleko osagaien markaketan eta ezagutzean; ubikitinak izan litezke proteina horietako batzuk [18].

Ugaztunen zeluletan ez bezala, mikroautofagia bidez gertatzen da lipofagia legamietan. Mota horretako lipofagian LTak zuzenean bakuoletara bideratzen dira, bertan beren edukia hidrolizatua izan dadin. Azkeneko lipofagia mota da bereziena: fase geldikorreko lipofagia. Legamietan bakarrik deskribatu izan da eta zelulak kieszentzian sartuta aktibatzen da. LTak gradualki bakuoletan barneratu eta metatzen dira kolesteroletan aberastu- 
tako domeinuen bidez. Azken horretan LTen suntsipen-abiadura motelagoa da beste lipofagia motetan baino [16].
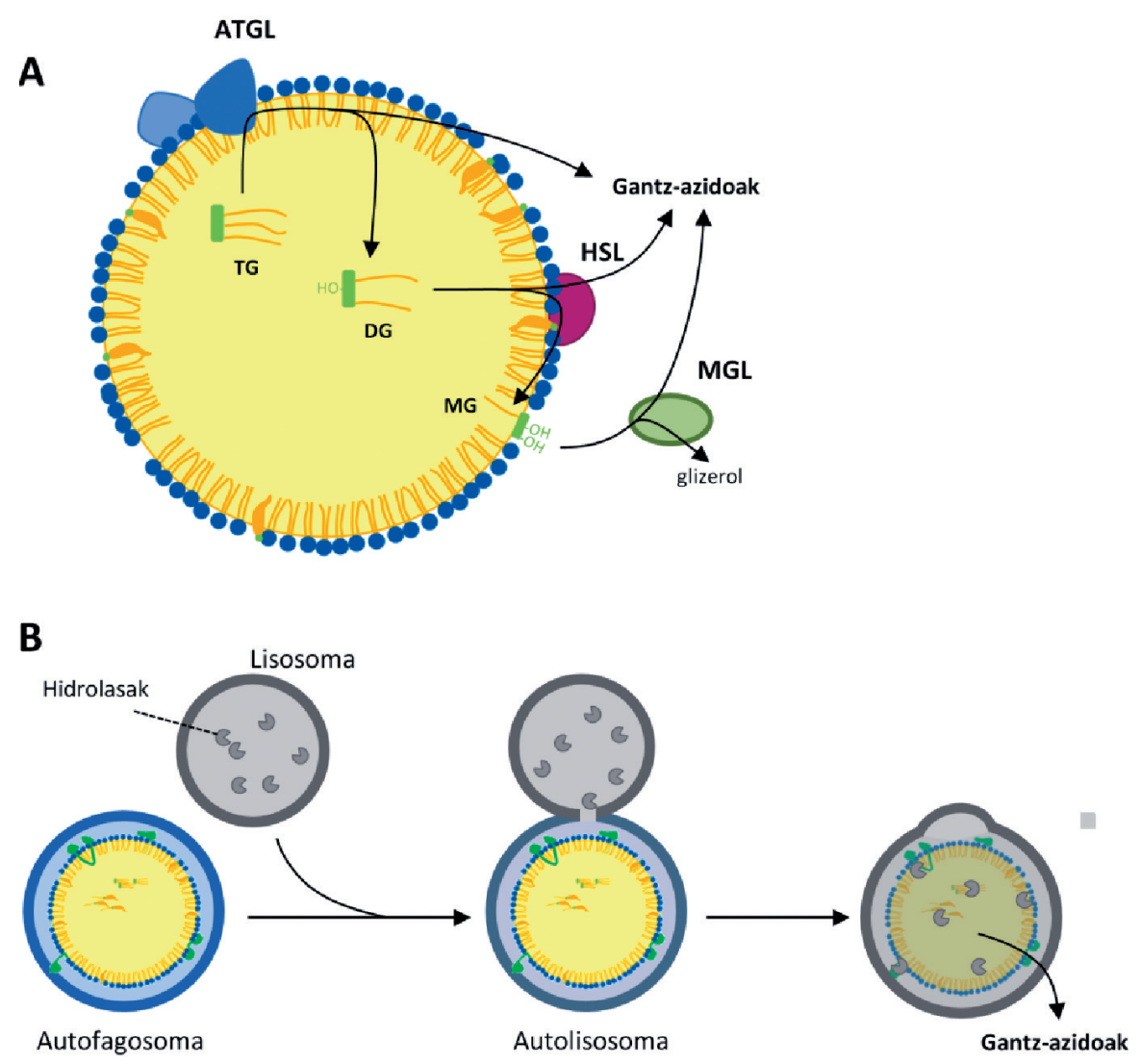

3. irudia. Lipido-tanten lipidoen erabilera eta suntsitzea. A: Lipolisi prozesuan trazilglizerolen (TG) gantz-azidoak 3 entzimen ekintza sekuentzialak askatzen ditu. DG: diazilglizerolak, MG: monoazilglizerolak, ATGL: adiposoko TG lipasa, HSL: hormonekiko sentikorra den lipasa, MGL: MG lipasa. B: Autofagiaren (lipofagiaren) bidez ere degrada daitezke lipido-tantetan metatutako TGak. Kasu horretan lisosometako lipasa azidoei esker gertatzen da gantz-azidoen askapena.

\section{FUNTZIO EZKANONIKOAK}

LTen proteomaren azterketa ugari egin dira [19-22] zenbait organismo eta zelula motatan. Azterketa horietan aurkitu da LTek, lipidoen kudeaketarako beharrezkoak diren proteinez gain, badituztela oso prozesu ezberdinetan parte hartzen duten proteinak ere, besteak beste zitosoleko, nukleoko, 
EEko edo mitokondrioko proteinak. Era berean, proposatu da gaizki tolestutako proteinen behin-behineko biltegi izan litezkeela. LTetako proteina batzuek proteinak ainguratzeko eta bahitzeko funtzioa daukate. Horien artean FSP27 proteina dago. FSP27-k NFAT5 (nuclear factor of activated $T$ cells 5; aktibatutako T zelulen faktore nuklearra 5) transkripzio-faktorea bahitzen du, eta nukleora sartzea oztopatuz bere jarduera murrizten du [23]. NFAT5 transkripzio-faktoreak estres hipertonikoari eta estimulu ugariri aurre egiteko erregulatzen du gene-adierazpena [24, 25] eta, beraz, LTek homeostasiaren modulazioan dihardutela esan daiteke.

Gene-adierazpena modulatzeko beste modu bat LTetan lipidoen bidezko seinalizazio bideak erregulatzea da. PPAR $\alpha$ (peroxisome proliferator-activated receptor $\alpha$; peroxisomen ugaltzaileek aktibatutako hartzailea $\alpha$ ) hartzaile nuklearrak, lipido espezifikoak lotu ondoren, zenbait generen adierazpena erregulatzen du, eta ondorioz kontrolpean jartzen ditu lipidoen metaketa eta mobilizazioa, glukosaren metabolismoa, proliferazioa eta inflamazio-erantzuna [26]. PPAR $\alpha$-ren agonisten artean gantz-azidoak eta prostaglandinak daude; horien jatorria edozein izan daitekeela pentsa litekeen arren, Haemmerleren eta kideen arabera [27] kasu batzuetan LTetako ATGL lipasaren jarduera ezinbestekoa da PPAR $\alpha$ aktibatu dadin.

Kontu eztabaidatua da baina edonola, iradoki izan da LTek parte hartzen dutela erretikulu endoplasmatikoarekin erlazionatutako proteina-degradazioan (endoplasmic reticulum-associated protein degradation edo ERAD). Mekanismo horren bidez EEko proteinak ubikitinaziora eta proteasomaren bidezko degradaziora bideratzen dira. Jo-k eta kideek argitaratutakoaren arabera [28], AUP1 izeneko proteina (ancient ubiquitous protein 1; aitzinako non-nahiko proteina 1) LTetan koka daiteke eta bertara erakartzen ditu ubikitinazioan diharduten proteinetako batzuk; LTetatik bertatik, ubikitinizatu eta degradaziora bideratzen dituzte EEan dauden proteinak. Mekanismo horrek adibidez, 3-hidroxi-3-metilglutaril-A koentzima erreduktasa entzimaren degradazioan jokatzen du; degradazio hori erregulazio-puntu garrantzitsuena da kolesterolaren sintesi bidean [29].

Bakterioen aurka aritzen diren proteinak ere ainguratzen dituzte LTek. Hori da histonen kasua. 1950. hamarkadatik ezagutzen da bakterio ezberdin askoren aurkako in vitro jarduera dutela histonek [30]. Drosophila melanogaster euliaren enbrioien LTek histona-biltegi gisa jarduten dute [20]. Ekidin egiten dituzte kromatinari lotzen ez zaizkion histonek eragin ditzaketen kalte toxikoak, eta bermatzen dute enbrioiaren zelulek behar bezainbesteko histona izango dituztela mitosi prozesuak aurrera eramateko. Gainera, patogenoekin erlazionatutako eredu molekularren (pathogen-associated molecular pattern edo PAMP) presentzian histonak LTetatik askatzen dira eta bakterioen heriotza eragin dezakete zelula barruan [31]. 
LTak ezinbestekoak dira birus batzuen mihiztadura egokia gerta dadin. Hori da $\mathrm{C}$ hepatitisaren birusaren kasua; birusa zelulara sartu eta bere geneak adierazten hasten direnean bi proteina LTetan metatzen dira, muinproteina eta NS5A (nonstructural protein 5A; egiturazkoa ez den proteina 5A) izenekoa. Ondoren birusen proteinek LTa erabiltzen dute mihiztadura-plataforma gisa [32]. Kasu horretan, beraz, LTek parte hartzen dute ostalariarentzat kaltegarria den birusaren zabalkuntzan.

\section{BIBLIOGRAFIA}

[1] THIAM A.R., FARESE R.V.Jr eta WALTHER T.C. 2013. «The biophysics and cell biology of lipid droplets». Nature Reviews. Molecular Cell Biology, $14,775-786$.

[2] SKINNER J.R., SHEW T.M., SCHWARTZ D.M., TZEKOV A., LEPUS C.M., ABUMRAD N.A. eta WOLINS N.E. 2009. «Diacylglycerol enrichment of endoplasmic reticulum or lipid droplets recruits perilipin 3/TIP47 during lipid storage and mobilization». The Journal of Biological Chemistry, 284, 30941-30948.

[3] KASSAN A., HERMS A., FERNANDEZ-VIDAL A., BOSCH M., SCHIEBER N.L., REDDY B.J., FAJARDO A., GELABERT-BALDRICH M., TEBAR F., ENRICH C., GROSS S.P., PARTON R.G. eta POL A. 2013. «Acyl-CoA synthetase 3 promotes lipid droplet biogenesis in ER microdomains». The Journal of Cell Biology, 203, 985-1001.

[4] GONG J., SUN Z., WU L., XU W., SCHIEBER N., XU D., SHUI G., YANG H., PARTON R.G. eta LI P. 2011. «Fsp27 promotes lipid droplet growth by lipid exchange and transfer at lipid droplet contact sites». The Journal of Cell Biology, 195, 953-963.

[5] SUN Z., GONG J., WU H., XU W., WU L., XU D., GAO J., WU J.W., YANG H., YANG M. eta LI P. 2013. «Perilipin1 promotes unilocular lipid droplet formation through the activation of Fsp27 in adipocytes». Nature Communications, 4, 1594.

[6] WU L., XU D., ZHOU L., XIE B., YU L., YANG H., HUANG L., YE J., DENG H., YUAN Y.A., CHEN S. eta LI P. 2014. «Rab8a-AS160-MSS4 regulatory circuit controls lipid droplet fusion and growth». Developmental Cell, 30, 378-393.

[7] JIN Y., MCFIE P.J., BANMAN S.L., BRANDT C. eta STONE S.J. 2014. «Diacylglycerol acyltransferase-2 (DGAT2) and monoacylglycerol acyltransferase-2 (MGAT2) interact to promote triacylglycerol synthesis». The Journal of Biological Chemistry, 289, 28237-28248.

[8] ZEHMER J.K., BARTZ R., LIU P. eta ANDERSON R.G. 2008. «Identification of a novel $\mathrm{N}$-terminal hydrophobic sequence that targets proteins to lipid droplets». Journal of Cell Science, 121, 1852-1860. 
[9] INGELMO-TORRES M., GONZALEZ-MORENO E., KASSAN A., HANZAL-BAYER M., TEBAR F., HERMS A., GREWAL T., HANCOCK J.F., ENRICH C., BOSCH M., GROSS S.P., PARTON R.G. eta POL A. 2009. «Hydrophobic and basic domains target proteins to lipid droplets». Traffic, 10, 1785-1801.

[10] WILFLING F., WANG H., HAAS J.T., KRAHMER N., GOULD T.J., UCHIDA A., CHENG J.X., GRAHAM M., CHRISTIANO R., FROHLICH F., LIU X., BUHMAN K.K., COLEMAN R.A., BEWERSDORF J., FARESE R.V.,Jr eta WALTHER T.C. 2013. «Triacylglycerol synthesis enzymes mediate lipid droplet growth by relocalizing from the ER to lipid droplets». Developmental Cell, 24, 384-399.

[11] KRAHMER N., GUO Y., WILFLING F., HILGER M., LINGRELL S., HEGER K., NEWMAN H.W., SCHMIDT-SUPPRIAN M., VANCE D.E., MANN M., FARESE R.V.Jr eta WALTHER T.C. 2011. «Phosphatidylcholine synthesis for lipid droplet expansion is mediated by localized activation of CTP:phosphocholine cytidylyltransferase». Cell Metabolism, 14, 504515.

[12] WOLINS N.E., BRASAEMLE D.L. eta BICKEL P.E. 2006. «A proposed model of fat packaging by exchangeable lipid droplet proteins». FEBS Letters, 580, 5484-5491.

[13] SONI K.G., MARDONES G.A., SOUGRAT R., SMIRNOVA E., JACKSON C.L. eta BONIFACINO J.S. 2009. «Coatomer-dependent protein delivery to lipid droplets». Journal of Cell Science, 122, 1834-1841.

[14] MARTINEZ-LOPEZ N. eta SINGH R. 2015. «Autophagy and Lipid Droplets in the Liver». Annual Review of Nutrition, 35, 215-237.

[15] SINGH R. eta CUERVO A.M. 2012. «Lipophagy: connecting autophagy and lipid metabolism». International Journal of Cell Biology, 2012, 282041.

[16] WANG C.W. 2015. «Lipid droplets, lipophagy, and beyond». Biochimica Et Biophysica Acta, 1861, 793-805.

[17] SINGH R., KAUSHIK S., WANG Y., XIANG Y., NOVAK I., KOMATSU M., TANAKA K., CUERVO A.M. eta CZAJA M.J. 2009. «Autophagy regulates lipid metabolism». Nature, 458, 1131-1135.

[18] KIRKIN V., MCEWAN D.G., NOVAK I. eta DIKIC I. 2009. "A role for ubiquitin in selective autophagy». Molecular Cell, 34, 259-269.

[19] BRASAEMLE D.L., DOLIOS G., SHAPIRO L. eta WANG R. 2004. «Proteomic analysis of proteins associated with lipid droplets of basal and lipolytically stimulated 3T3-L1 adipocytes». The Journal of Biological Chemistry, 279, 46835-46842.

[20] CERMELLI S., GUO Y., GROSS S.P. eta WELTE M.A. 2006. «The lipiddroplet proteome reveals that droplets are a protein-storage depot». Current Biology : CB, 16, 1783-1795.

[21] BOUCHOUX J., BEILSTEIN F., PAUQUAI T., GUERRERA I.C., CHATEAU D., LY N., ALQUB M., KLEIN C., CHAMBAZ J., ROUSSET M., LACORTE J.M., MOREL E. eta DEMIGNOT S. 2011. «The proteome of 
cytosolic lipid droplets isolated from differentiated Caco-2/TC7 enterocytes reveals cell-specific characteristics». Biology of the Cell, 103, 499-517.

[22] D'AQUILA T., SIROHI D., GRABOWSKI J.M., HEDRICK V.E., PAUL L.N., GREENBERG A.S., KUHN R.J. eta BUHMAN K.K. 2015. «Characterization of the proteome of cytoplasmic lipid droplets in mouse enterocytes after a dietary fat challenge». PloS One, 10, e0126823.

[23] UENO M., SHEN W.J., PATEL S., GREENBERG A.S., AZHAR S. eta KRAEMER F.B. 2013. «Fat-specific protein 27 modulates nuclear factor of activated T cells 5 and the cellular response to stress». Journal of Lipid Research, 54, 734-743.

[24] ARAMBURU J., DREWS-ELGER K., ESTRADA-GELONCH A., MINGUILLON J., MORANCHO B., SANTIAGO V. eta LOPEZ-RODRIGUEZ C. 2006. «Regulation of the hypertonic stress response and other cellular functions by the Rel-like transcription factor NFAT5». Biochemical Pharmacology, 72, 1597-1604.

[25] HALTERMAN J.A., KWON H.M. eta WAMHOFF B.R. 2012. «Tonicity-independent regulation of the osmosensitive transcription factor TonEBP (NFAT5)». American Journal of Physiology. Cell Physiology, 302, C1-8.

[26] FEIGE J.N., GELMAN L., MICHALIK L., DESVERGNE B. eta WAHLI W. 2006. «From molecular action to physiological outputs: peroxisome proliferator-activated receptors are nuclear receptors at the crossroads of key cellular functions». Progress in Lipid Research, 45, 120-159.

[27] HAEMMERLE G., MOUSTAFA T., WOELKART G., BUTTNER S., SCHMIDT A., VAN DE WEIJER T., HESSELINK M., JAEGER D., KIENESBERGER P.C., ZIERLER K., SCHREIBER R., EICHMANN T., KOLB D., KOTZBECK P., SCHWEIGER M., KUMARI M., EDER S., SCHOISWOHL G., WONGSIRIROJ N., POLLAK N.M., RADNER F.P., PREISS-LANDL K., KOLBE T., RULICKE T., PIESKE B., TRAUNER M., LASS A., ZIMMERMANN R., HOEFLER G., CINTI S., KERSHAW E.E., SCHRAUWEN P., MADEO F., MAYER B. eta ZECHNER R. 2011. «ATGL-mediated fat catabolism regulates cardiac mitochondrial function via PPAR-alpha and PGC-1». Nature Medicine, 17, 1076-1085.

[28] JO Y., HARTMAN I.Z. eta DEBOSE-BOYD R.A. 2013. «Ancient ubiquitous protein-1 mediates sterol-induced ubiquitination of 3-hydroxy-3-methylglutaryl CoA reductase in lipid droplet-associated endoplasmic reticulum membranes». Molecular Biology of the Cell, 24, 169-183.

[29] HARTMAN I.Z., LIU P., ZEHMER J.K., LUBY-PHELPS K., JO Y., ANDERSON R.G. eta DEBOSE-BOYD R.A. 2010. «Sterol-induced dislocation of 3-hydroxy-3-methylglutaryl coenzyme A reductase from endoplasmic reticulum membranes into the cytosol through a subcellular compartment resembling lipid droplets». The Journal of Biological Chemistry, 285, 1928819298. 
[30] HIRSCH J.G. 1958. «Bactericidal action of histone». The Journal of Experimental Medicine, 108, 925-944.

[31] ANAND P., CERMELLI S., LI Z., KASSAN A., BOSCH M., SIGUA R., HUANG L., OUELLETTE A.J., POL A., WELTE M.A. eta GROSS S.P. 2012. «A novel role for lipid droplets in the organismal antibacterial response». eLife, 1, e00003.

[32] FILIPE A. eta MCLAUCHLAN J. 2015. «Hepatitis C virus and lipid droplets: finding a niche». Trends in Molecular Medicine, 21, 34-42. 